\title{
DISAIN SISTEM SCADA DI INSTALASI PENGOLAHAN AIR BERSIH UNTUK KEBUTUHAN DOMESTIK DI SUATU KAWASAN INDUSTRI
}

\author{
Oleh : \\ Heru Dwi Wahjono \\ Peneliti Pusat Teknologi Lingkungan, BPPT
}

\begin{abstract}
Industrial area represents location where some industries operate in one same area region. Usually an industrial area besides there are factory also there are office and housing. To fulfill domestic clean water required by housing and office, usually the organizer of industrial area have developed a Water Treatment Plant (WTP) with source of raw water which come from a river emitting a stream of around area. The increasing of domestic clean water needs has pushed management to increase the production of clean water by the existing WTP. Besides that, to increase the quality of clean water service to the domestic exist in industrial area, hence felt important to develop a system of SCADA to manage existing process in the WTP. As step early is to identify and plan the design system of SCADA for domestic WTP. From the result of development planning, the SCADA can be developed step by step according to the project plan and existing budget.
\end{abstract}

Kata kunci : Water Treatment Plant (WTP), Instalasi Pengolahan Air (IPA), Kebutuhan Air Bersih Domestik Perumahan, Supervisory Control And Data Acquisition (SCADA).

\section{PENDAHULUAN}

\subsection{Latar Belakang}

Kawasan Industri seperti Pulogadung, Cikarang, Jababeka, dan MM2100 merupakan kawasan industri besar di Jawa Barat yang telah menerapkan pengembangan kawasan industri yang berwawasan lingkungan. Sebagai bentuk kepedulian terhadap lingkungan di kawasan industri ini telah membangun dan mengoperasikan beberapa unit Instalasi Pengolahan Air Limbah (IPAL) dan beberapa unit Instalasi Pengolahan Air Bersih (IPA) di lingkungannya.

Dari hasil survei studi kasus yang telah dilakukan di Kawasan Industri Jababeka, menunjukkan bahwa untuk memenuhi kebutuhan air bersih perkantoran dan perumahan, kawasan industri ini telah memiliki dan mengelola unit Instalasi Pengolahan Air Bersih (WTP) dengan total kapasitas produksi kurang lebih 205 liter / detik ${ }^{1}$. Untuk mempertahankan dan meningkatkan kualitas pelayanan penyediaan air bersih, pihak manajemen kawasan telah melakukan penyempurnaan teknologi yang digunakan untuk mengolah air baku yang semakin hari semakin menurun kualitasnya.

Saat ini tahapan proses pengolahan yang dilakukan di WTP semakin lengkap terbukti dengan kualitas air bersih yang dihasilkan hingga saat ini telah memenuhi baku mutu yang disyaratkan oleh pemerintah sesuai dengan SK Menteri Kesehatan No. 416/MENKES/1991. Hal ini tidak lepas dari sistem pengoperasian yang telah memenuhi standar KAN (Komite Akreditasi
Nasional) dan Pedoman Kebijakan Mutu ISO 9001:2000 yang telah diperoleh WTP ini.

Untuk lebih meningkatkan pelayanan dalam pengadaan air bersih dirasa perlu untuk meningkatkan pula sistem pengoperasian dan pemantauan di unit WTP domestik melalui suatu sistem pengendalian dan pemantauan pada setiap tahapan prosesnya. Dengan menerapkan teknologi SDADA (Supervisory Control And Data Acquisition), lingkup operasi dan pengawasan terhadap proses di WTP dapat dikendalikan dalam satu ruangan kendali dengan mudah.

\subsection{Tujuan dan Sasaran}

Kegiatan ini bertujuan untuk merancang suatu sistem SCADA yang dapat diaplikasikan di Instalasi Pengolahan Air suatu kawasan industri yang melayani kebutuhan air bersih domestik. Adapun sasarannya adalah teridentifikasikannya kondisi existing peralatan dan perencanaan peralatan yang mendukung perancangan sistem SCADA di setiap tahapan proses di WTP ini.

\subsection{Lingkup Kegiatan}

Lingkup kegiatan yang dilaksanakan pada perancangan sistem SCADA adalah :

- Melakukan survei kondisi existing untuk mengamati proses pengolahan air yang ada.

- Inventarisasi peralatan-peralatan proses yang terdiri dari pompa, dosing, blower, dan sensor-sensor yang telah terpasang.

- Lokasi kerja meliputi keseluruhan unit proses di WTP, yaitu : Air Baku (Raw Water Intake), 
Bahan Kimia dan ruang Dosing (Chemical \& Dosing Room), Flokulator, Clarifier, Filtrasi (Filtration), ruang disinfeksi (Disinfection room), Bak penampung (Reservoir), dan ruang pompa distribusi (Water Supply Pump) 1). Gambar 1 menunjukkan denah lokasi masing-masing unit proses di WTP domestik.

- Menyusun perencanaan sistem hardware dan software untuk SCADA dengan usulan tahapan pembangunan.

\section{METODOLOGI}

Pelaksanaan kegiatan perancangan sistem SCADA untuk WTP domestik mengikuti metodologi sebagai berikut :

1) Survei Lapangan. Survei ini dilakukan untuk mengetahui secara detail tentang keadaan di lokasi WTP domestik, khususnya mengenai proses pengolahan air bersih, jumlah peralatan unit proses yang ada (existing systems), fungsi dan kondisi peralatan unit proses serta memperoleh masukan dalam melakukan identifikasi kebutuhan pengembangan sistem baru (proposed system).

2) Analisa Sistem. Analisa sistem dilakukan terhadap proses pengolahan air untuk menentukan parameter pantau dan lokasi pemantauan di setiap tahapan proses. Analisis dilakukan juga terhadap peralatan sensor yang ada untuk mengetahui metode monitoring dan pengembangannya.

3) Rancangan/Disain Sistem. Perancangan sistem hardware dan sistem software SCADA untuk mendukung monitoring dan controling peralatan yang ada secara online dan realtime.

\section{TINJAUAN LITERATUR}

SCADA adalah suatu sistem yang dirancang untuk melakukan pengawasan dan pengendalian suatu proses secara terintegrasi, yang mencakup fungsi monitoring dan pengumpulan data. Supervisory Control mencakup kemampuan untuk melakukan perintah Start / Stop, mengubah parameter suatu proses serta mengubah set point alarm. Sedangkan Data Acquisition adalah kemampuan untuk merekam dan menampilkan kondisi dan jalannya suatu proses sehingga data yang direkam dapat ditampilkan untuk evaluasi lebih lanjut ${ }^{2)}$.

\section{Keuntungan menggunakan SCADA} antara lain dapat memaksimalkan produksi, memperbaiki kualitas produksi dan mengurangi biaya operasi dan perawatan. Selain itu, keuntungan yang paling utama adalah dapat mengetahui keseluruhan sistem proses secara langsung (online dan real time) sehingga dapat membantu dan mempermudah manajemen dalam mengambil keputusan berkaitan dengan proses pelayanan air bersih di lingkungan suatu kawasan perumahan.

Sistem instrumentasi dan kendali di instalasi pengolahan air bersih memiliki tujuan untuk mengoperasikan dan mengendalikan fasilitas pengolahan yang ada mulai dari intake / sumber air baku sampai dengan pendistribusian dengan aman, reliabilitas dan secara bersamaan dapat membantu manajemen dalam melaksanakan pengelolaan sebuah instalasi pengolahan air 2). Diagram alir monitoring dan controling untuk WTP perumahan beserta parameter pemantauan dan pengendalian yang seharusnya dilakukan di setiap tahapan proses pengolahan air ditunjukkan pada gambar 2 .

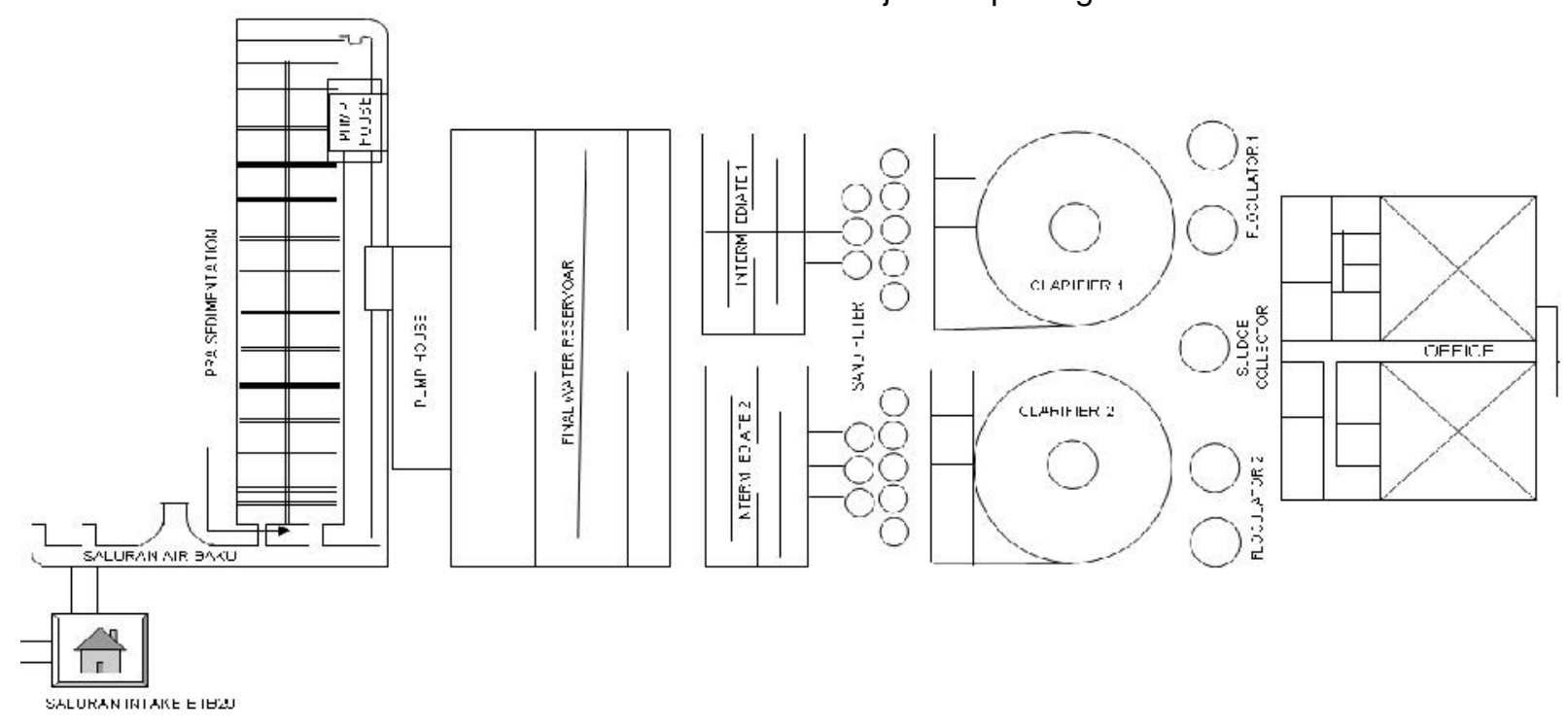

Gambar 1. Denah Lokasi Masing-Masing Unit Proses Di WTP Domestik 


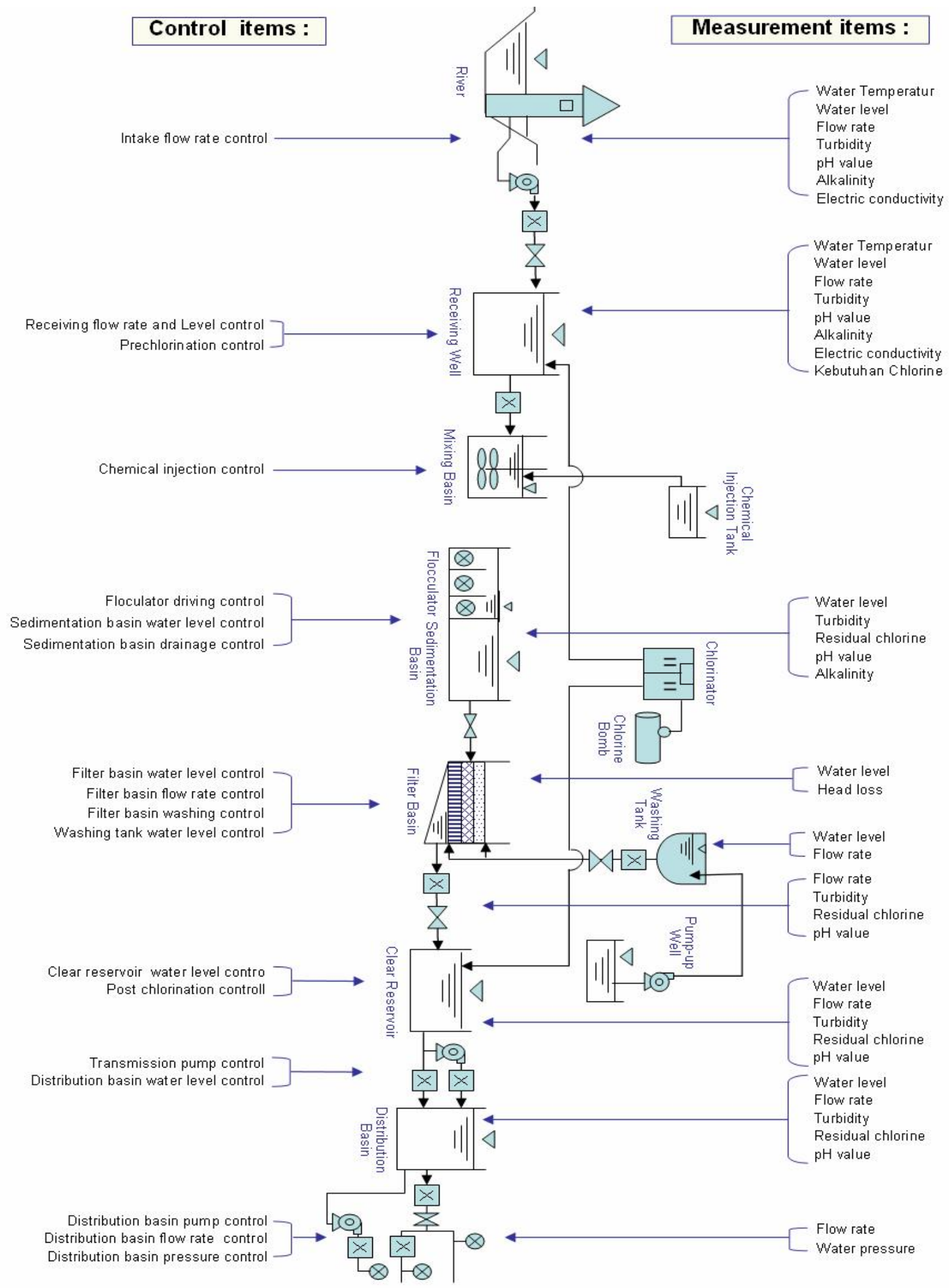

Gambar 2. Diagram Alir Monitoring dan Controling Untuk WTP 


\section{HASIL DAN PEMBAHASAN}

Tahap pekerjaan yang dilaksanakan untuk kegiatan perencanaan disain sistem SCADA di WTP domestik adalah sebagai berikut:

\subsection{Survei dan Analisa Sistem Proses}

Agar sistem SCADA yang diterapkan dapat bekerja sesuai dengan tujuan dan sasaran yang diharapkan, maka telah dilakukan survei dan analisa terhadap masing-masing proses kerja di unit WTP domestik. Kegiatan ini bertujuan untuk mendapatkan parameter pemantauan kualitas dan kuantitas air serta parameter fisik yang berkaitan dengan sistem kontrol peralatan di WTP domestik. Gambar 3 berikut ini adalah diagram alir proses pengolahan air di WTP domestik dan posisi peletakan sensor kualitas air.

Lokasi penempatan unit sensor kualitas dan kuantitas air ditinjau berdasarkan arah aliran dan proses pengolahan air pada WTP adalah sebagai berikut :

- N0 (Node 0) diletakkan di intake air baku dengan memasang sensor kualitas air $(\mathrm{pH}$ dan NTU) untuk mengetahui perubahan kualitas dengan segera. CCTV camera digunakan untuk melihat situasi di sekitar lokasi intake. Wireless digunakan sebagai sistem media pengiriman data kualitas dan data gambar ke ruang kontrol.
- N1 (Node 1) diletakkan di saluran dari intake air baku menuju unit prasedimentasi di dalam halaman WTP dengan memasang sensor kualitas air (pH dan NTU).

- $\quad$ N2 (Node 2) diletakkan di bagian akhir arah aliran bak prasedimentasi dengan memasang sensor kualitas air $(\mathrm{pH}, \mathrm{NTU}$, Flow, Level, dan Residual Chlorine).

- N3 (Node 3) diletakkan di bak flocculator dengan memasang sensor $\mathrm{pH}$ untuk mengetahui besar dosis penambahan koagulan yang diperlukan dari tangki koagulan di dalam ruang bahan kimia.

- N4 (Node 4) diletakan di bak clarifier dengan mengamati kualitas air (NTU, pH, dan TSS)

- N5 (Node 5) diletakkan di outlet masingmasing grafitasi filter dengan mengamati head lost/level meter serta nilai NTU untuk mengetahui kinerja media pada masingmasing filter, sehingga operator akan tahu kapan penggantian media filter diperlukan.

- N6 (Node 6) diletakkan di bak reservoir dengan memasang sensor NTU, Residual Chlorine, $\mathrm{pH}$ dan level meter.

- $\quad$ N7 (Node 7) diletakkan di saluran distribusi ke tenant dengan mengamati Flow rate, Tekanan dan Residual Chlorine.

- $\quad$ N8 (Node 8) diletakkan di ruang bahan kimia dengan memasang sensor Flow rate dan Level meter untuk mengetahui stok bahan kimia di setiap tangki koagulan yang ada.

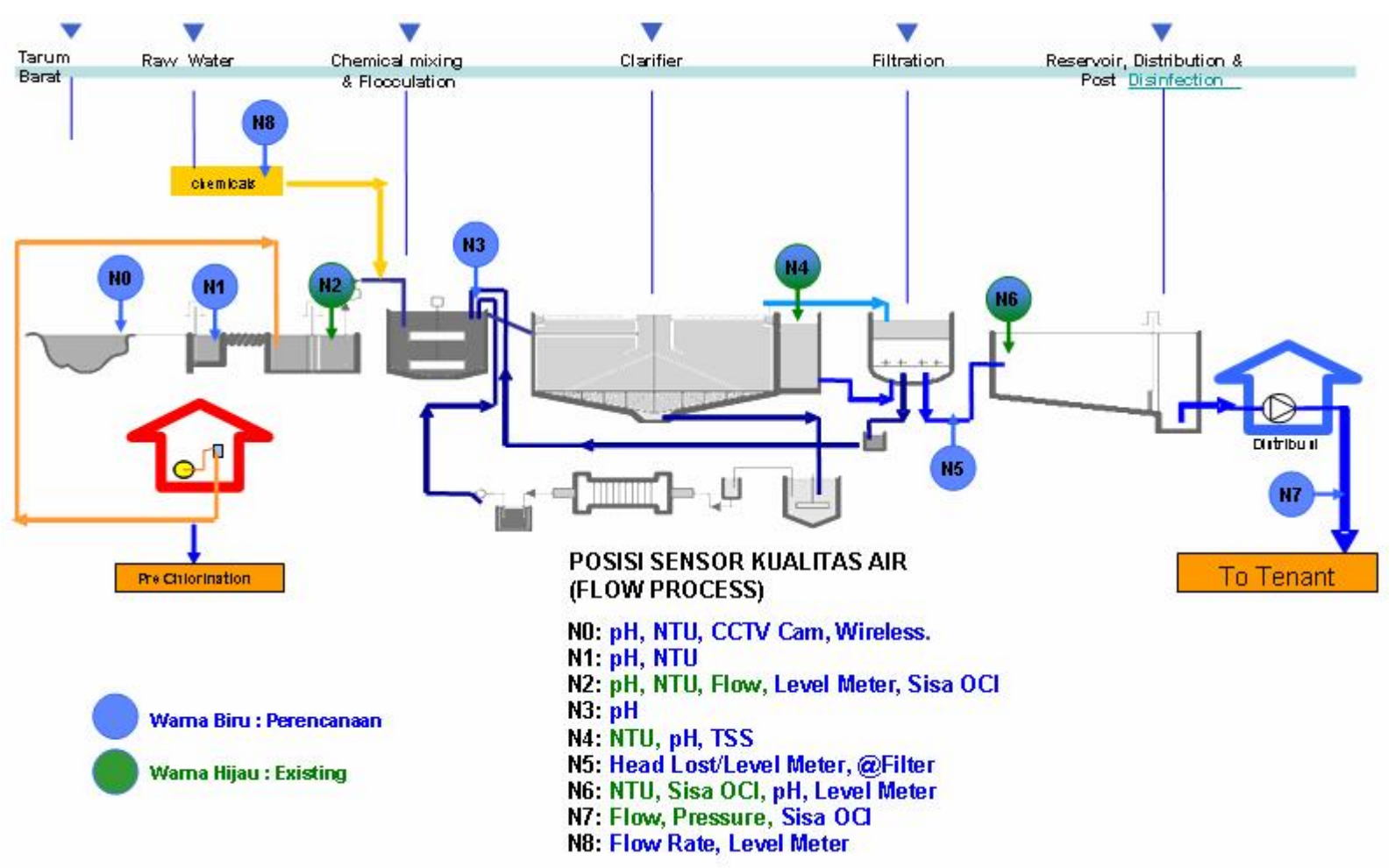

Gambar 3. Diagram Alir Proses Pengolahan Air dan Posisi Sensor Kualitas Air 
- Sistem media pengiriman data untuk lokasi N1 sampai lokasi N8 adalah dengan memakai sistem jaringan kabel.

Sedangkan untuk mengetahui status kerja (On/Off) peralatan pompa air baku, pompa booster chlorine, pompa backwash pompa distribusi, pompa dosing koagulan, mixer flocculator dan mixer clarifier yang ada di WTP perumahan akan digunakan inverter yang ada atau dengan membuat inverter baru untuk peralatan yang belum memilikinya.

\subsection{Rancangan Sistem}

Berdasarkan hasil analisa sistem proses pengolahan air di WTP domestik, kemudian dilakukan perencanaan dan disain terhadap sistem monitoring dan control di WTP domestik. Disain sistem SCADA dapat dikelompokkan ke dalam tiga kelompok disain, yaitu :

a. Parameter Kualitas/Kuantitas Air. Disain sistem untuk monitoring dan control data kualitas dan kuantitas air yang ada di setiap proses WTP, yang meliputi parameter seperti $\mathrm{pH}$, kekeruhan, TSS, residual chlorine, flow/debit, tekanan dan tinggi muka air (level)

b. Status Peralatan Pompa. Disain sistem untuk monitoring dan control peralatan kelistrikan yang terdiri dari pompa air, pompa dosing, blower udara, mixer, \& konsumsi energi listrik.

c. Software SCADA. Disain sistem software untuk monitoring dan controling sistem SCADA di WTP. Disain ini terdiri dari diagram pengoperasian software dan rancangan user interface software.
Gambar 4 di bawah ini adalah hasil perencanaan disain terhadap proses pengolahan air di WTP perumahan dan posisi peletakan sensor kualitas air disesuaikan dengan layout proses di lokasi WTP. Kondisi existing lokasi yang sudah memiliki sensor kualitas air dan lokasi penempatan sensor baik yang sudah ada maupun yang baru dapat dilihat dari gambar ini juga.

Perhitungan jumlah titik / node monitoring kualitas air pada WTP domestik (Tabel 1) telah disesuaikan dengan jumlah tahapan proses pengolahan air, dimana kondisi existing proses pengolahan air tersebut dilakukan secara paralel dua line proses. Warna hijau pada gambar menunjukkan kondisi existing peralatan sensor yang ada dan warna biru menunjukkan perencanaan disain pengembangan peralatan sensor yang akan diusulkan untuk melengkapi sistem SCADA.

Tabel 1. Jumlah Sensor Yang Diintegrasi di WTP Domestik

\begin{tabular}{|r|l|c|c|}
\hline No & \multicolumn{1}{|c|}{ Sensor } & Existing & Rencana \\
\hline 1. & pH & 1 & 10 \\
\hline 2. & Turbidity/Kekeruhan (NTU) & 4 & 22 \\
\hline 3. & Flow meter (Debit) & 7 & 4 \\
\hline 4. & Level meter & 16 & 24 \\
\hline 5. & Residual Chlorine & 1 & 3 \\
\hline 6. & TSS & - & 2 \\
\hline 7. & Pressure meter & 1 & 1 \\
\hline 8. & CCTV Camera & - & 1 \\
\hline
\end{tabular}

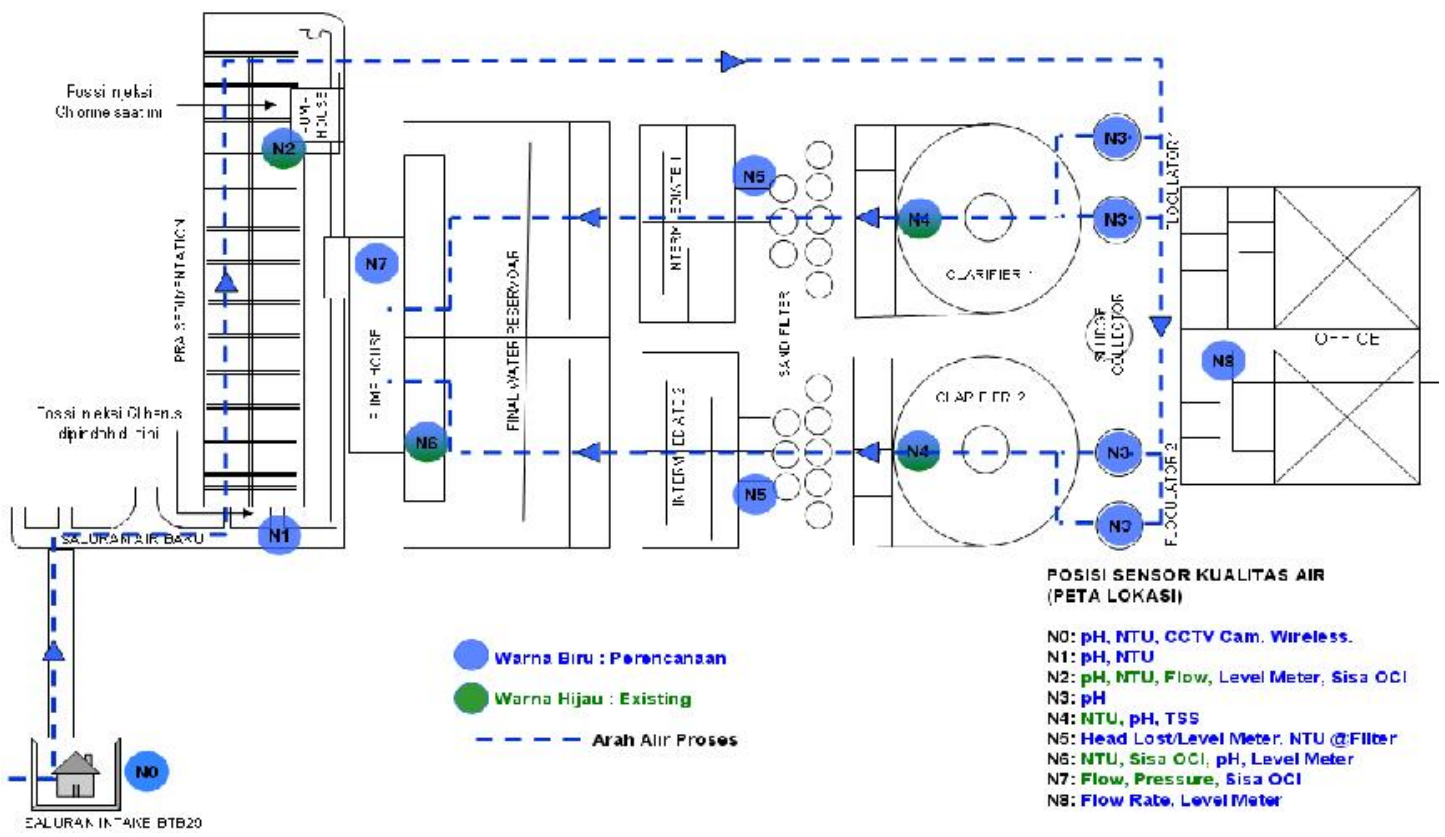

Gambar 4. Perencanaan Disain Penempatan Peralatan Sensor di WTP Domestik 
Foto-foto peralatan, lokasi dan jumlah parameter ukur di masing-masing titik pemantauan di WTP Domestik adalah sebagai berikut :
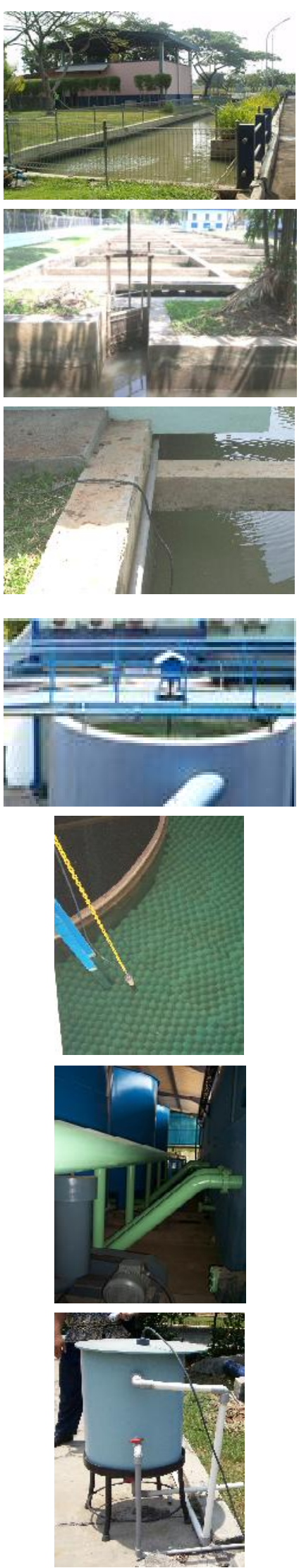

Intake RW - NO :

$\mathrm{pH}(1)$,

NTU (1),

CCTV Cam (1),

Wireless (1)

Saluran AB - N1 : $\mathrm{pH}(1), \mathrm{NTU}(1)$

Bak Prased. - N2 : $\mathrm{pH}$ (1),

NTU (1),

Flow (1),

Level (1),

Residual Chlorine

(1)

Flocculator - N3 : $\mathrm{pH}(4)$

Clarifier - N4 :

$\mathrm{pH}(2)$,

NTU (2),

TSS (2)

Grafitasi Filter - N5

Headlost/Level

Meter (16),

NTU (16)

Reservoir - N6 :

$\mathrm{pH}(1)$,

NTU (1),

Residual Chlorine

(1)

Level Meter (1)

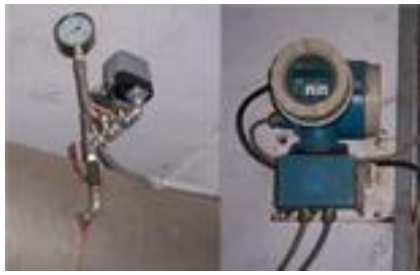

Sal. Distribusi - N7 :

Flow (1),

Pressure Meter (1),

Residual Chlorine

(1)

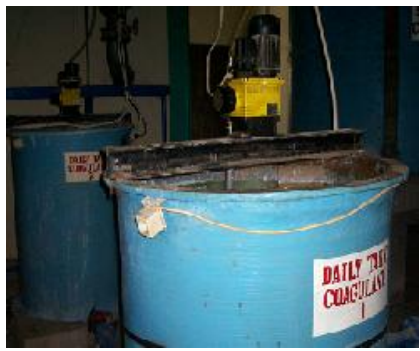

Ruang B.Kimia - N8

Flow (2),

Level Meter (6)

Peralatan kelistrikan seperti pompa dan mixer yang dimonitoring status kerjanya di setiap tahapan proses pengolahan air dapat dikelompok-kan ke dalam beberapa jenis pompa, yaitu : pompa air baku, pompa booster chlorine, pompa backwash, pompa distribusi, pompa dosing koagulan, mixer flocculator, mixer clarifier, kompresor, blower, dan electrict valve. Jumlah masing-masing peralatan ditunjukkan pada tabel 2.

Tabel 2. Jumlah Peralatan Kelistrikan Pompa Yang Diintegrasi di WTP Domestik

\begin{tabular}{|c|l|c|}
\hline No. & \multicolumn{1}{|c|}{ Peralatan } & Jumlah (unit) \\
\hline 1. & Pompa air baku & 6 \\
\hline 2. & Pompa booster chlorine & 2 \\
\hline 3. & Pompa backwash filter & 6 \\
\hline 4. & Pompa distribusi & 9 \\
\hline 5. & Pompa dosing koagulan & 2 \\
\hline 6. & Mixer flocculator & 4 \\
\hline 7. & Mixer clarifier & 2 \\
\hline 8. & Blower udara & 2 \\
\hline 9. & Kompresor & 2 \\
\hline 10. & KWH meter & 2 \\
\hline 11. & Electric Valve & 6 \\
\hline
\end{tabular}

Melalui inverter status operasi pompa akan dikirimkan ke ruang control. Gambar 5 menunjukkan kondisi existing peralatan kelistrikan seperti pompa dan lainnya di lokasi WTP domestik. Status pemakaian daya listrik oleh peralatan pompa dan lainnya selama proses pengolahan air di KWH induk dan di KWH dalam ruang distribusi juga dapat ditampilkan ke dalam sistem software SCADA. Gambar 6 menunjukkan lokasi rencana penempatan control panel yang sudah ada dan yang direncanakan untuk dibangun di WTP domestik. Masing-masing panel akan terhubung membentuk jaringan ke ruang kontrol utama. 


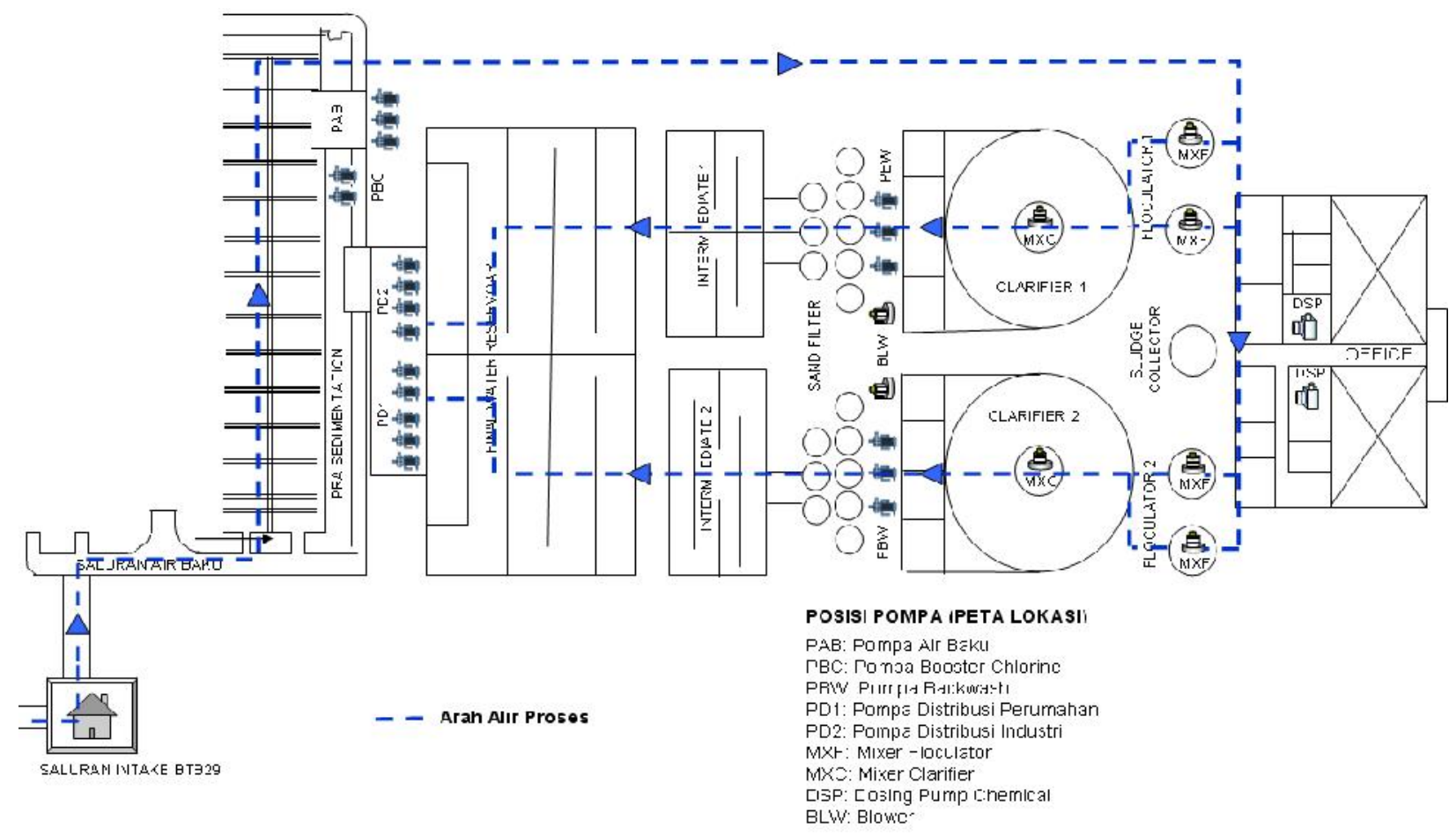

Gambar 5. Existing Peralatan Kelistrikan di WTP Domestik

Foto-foto peralatan kelistrikan di masingmasing lokasi pengolahan air di WTP Domestik adalah sebagai berikut :

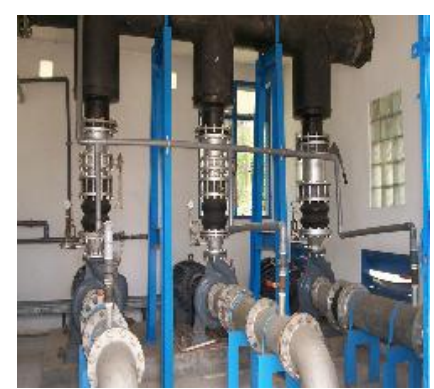

Pompa air baku $(\mathrm{PAB})$
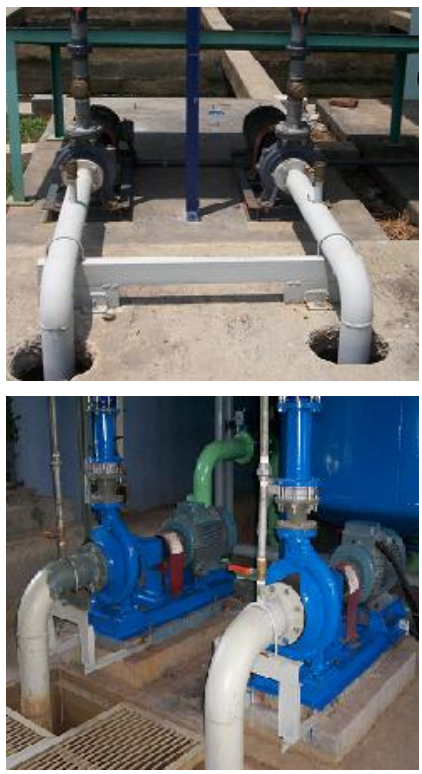

Pompa backwash filter (PBW)

\section{Pompa booster} chlorine (PBC)

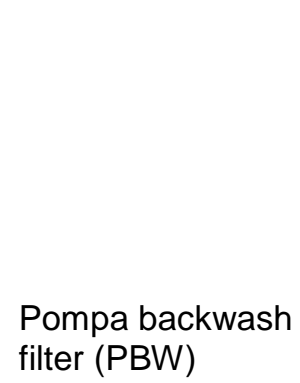

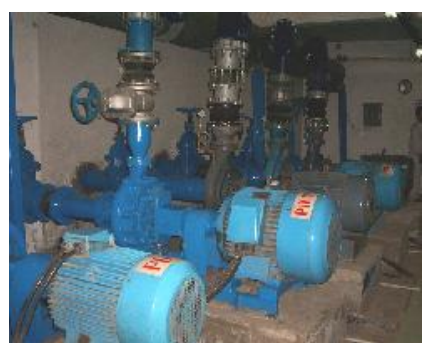

Pompa distribusi (PD)

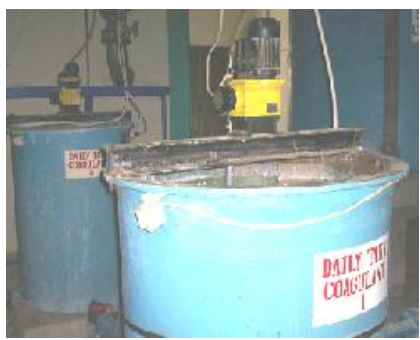

Pompa dosing koagulan (DSP)

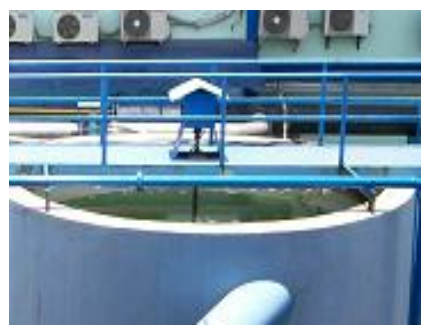

Mixer flocculator (MXF)

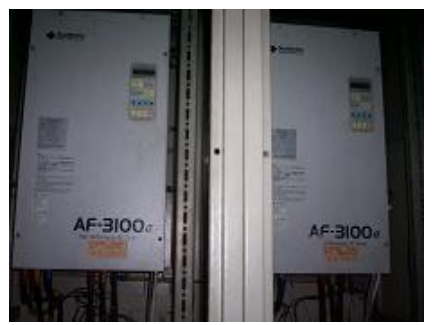




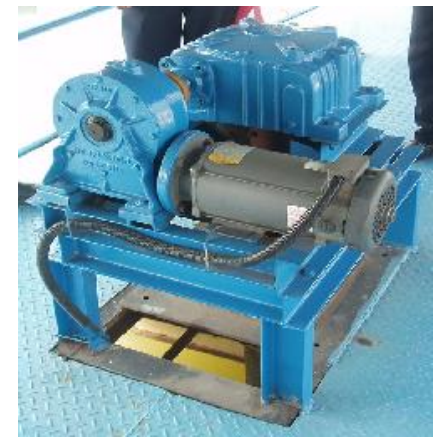

Mixer clarifier (MXC)

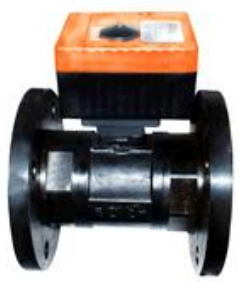

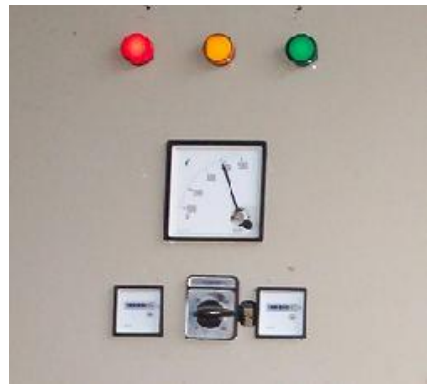

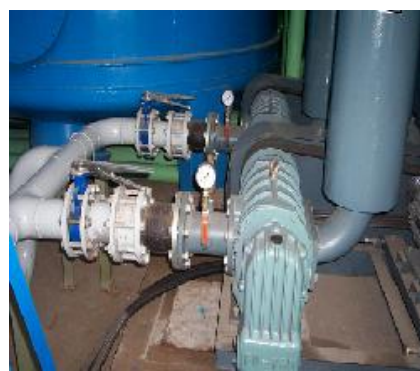

KWH meter

Blower udara

(BLW)

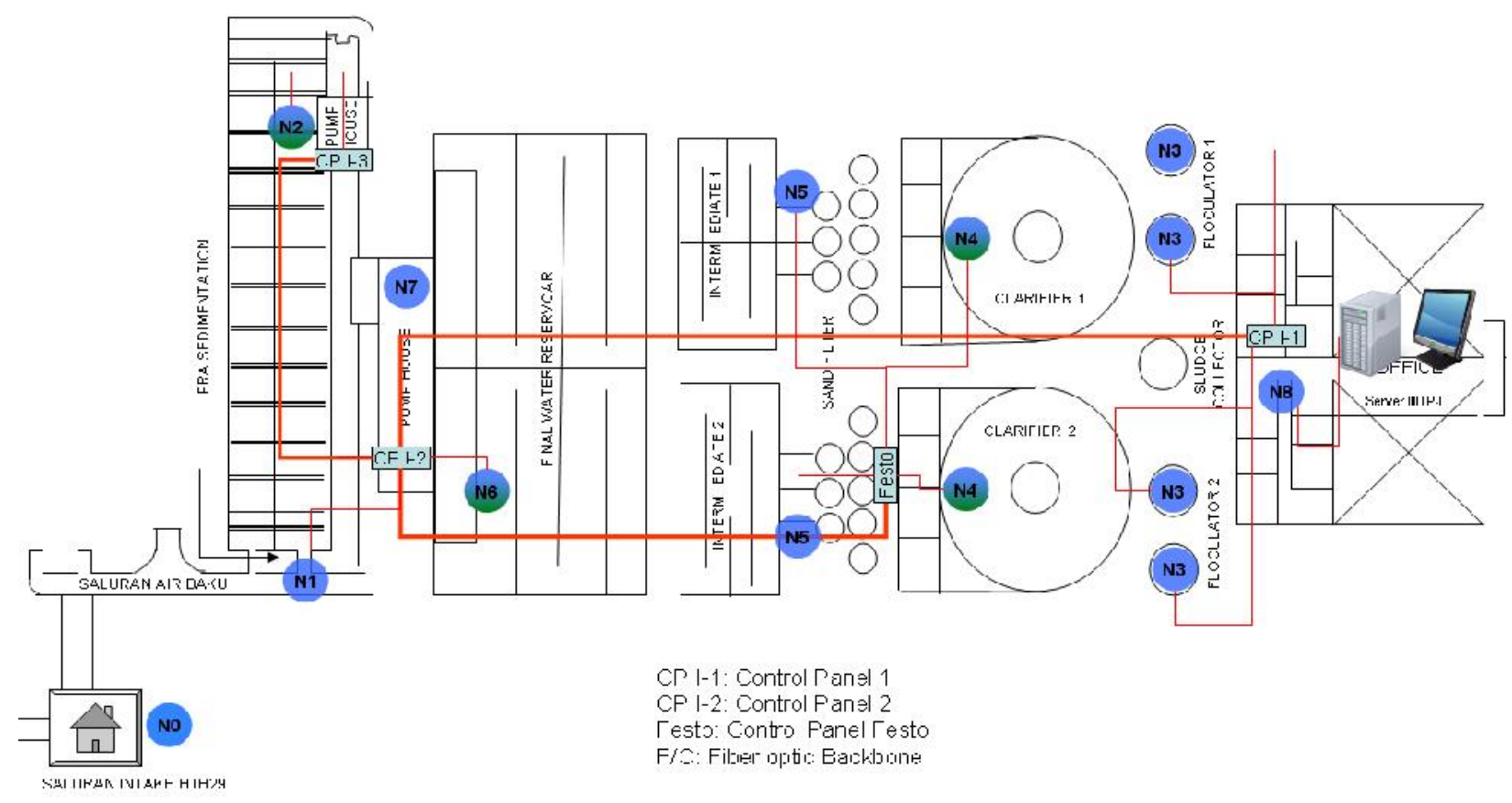

Gambar 6. Rencana Posisi Control Panel Sistem SCADA di WTP Domestik

Masing-masing control panel yang terdiri dari beberapa $L C$ (Lean Control) berfungsi untuk mengendalikan proses pengambilan data oleh sistem data logger di masing-masing lokasi penempatan sensor. Melalui kontrol panel ini data yang diambil kemudian dikirimkan ke pusat data di ruang kontrol. Data yang diterima, kemudian diolah oleh program database, sehingga dapat digunakan untuk menampilkan hasil pemantauan data pengukuran kualitas air dan status peralatan kelistrikan melalui layar monitor, panel monitor atau web browser yang ada di lokasi WTP Domestik. Diagram alir proses pengambilan data oleh Lean Control, pengolahan data dengan database software dan penampilan datanya dapat dilihat seperti pada gambar 7 .

Lean Control yang digunakan memiliki 8 port output, 8 por $t$ input, 16 virtual output coil dan 16 input contact yang dapat digunakan untuk berkomunikasi dengan peralatan monitoring atau peralatan kelistrikan lainnya. Setiap perubahan data hasil pengukuran sensor dan status peralatan kelistrikan yang ditimbulkan oleh pompa dan lainnya akan membangkitkan event/sinyal LC dan mengirimkan status baru untuk dibaca oleh event handler di data logger yang kemudian diteruskan ke pusat data untuk disimpan ke dalam database 


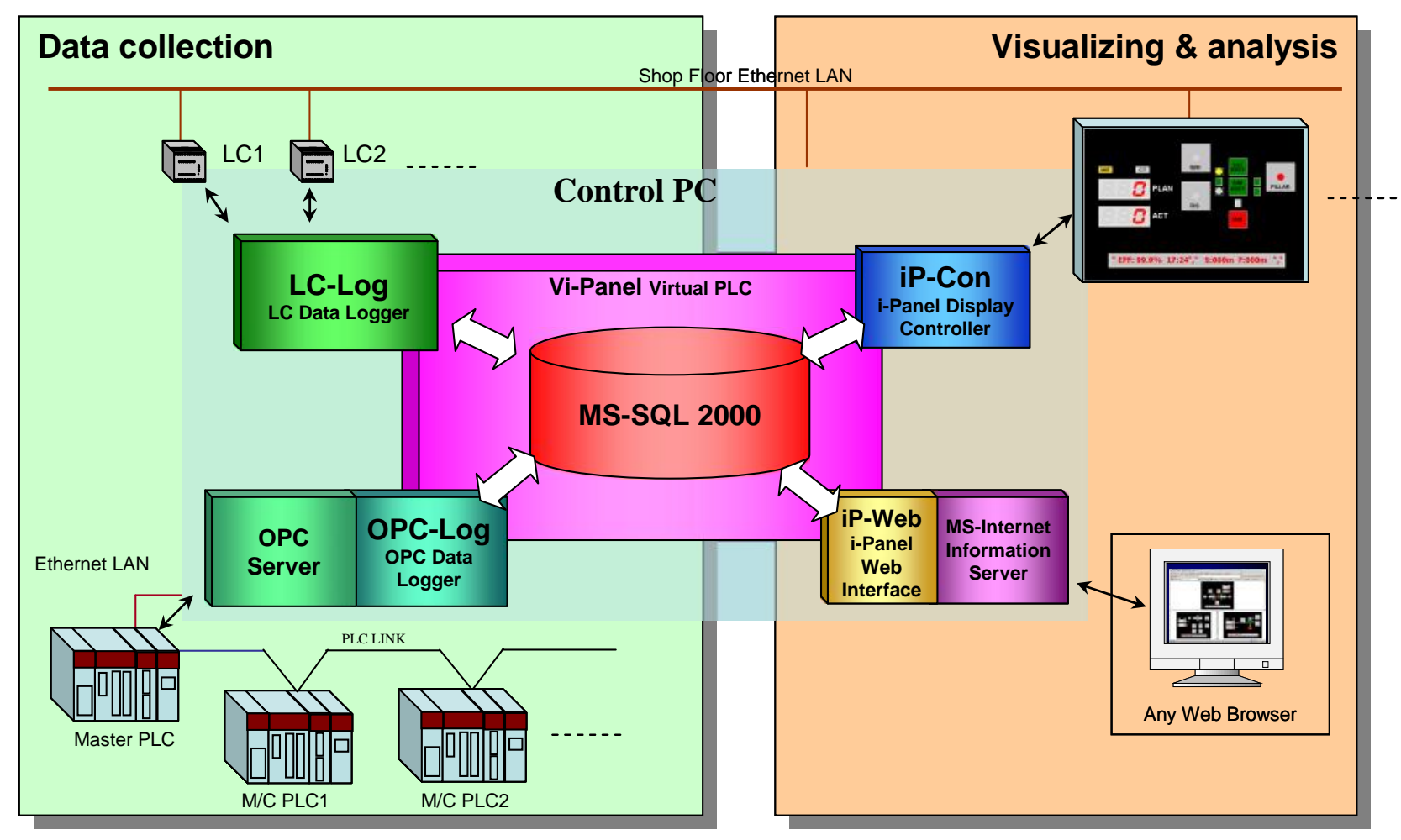

Gambar 7. Diagram Alir Sistem Pengolahan Data ${ }^{3)}$

\subsection{Perencanaan Pengembangan Sistem}

Perencanaan pengembangan dilakukan berdasarkan disain yang telah disempurnakan dan disepakati oleh pengelola WTP Domestik. Pengembangan dilakukan sesuai dengan tahapan sebagai berikut :

a. Tahap 1 : Integrasi peralatan yang sudah ada meliputi peralatan sensor dan peralatan pompa dan lain-lain. Pada tahap pertama ini perlu dilakukan pekerjaan-pekerjaan :

- Membuat protocol komunikasi disesuaikan dengan peralatan sensor yang ada.

- Membuat sistem controler / data logger untuk membaca status kerja peralatan pompa yang ada.

- Mengembangkan software SCADA versi pertama untuk montioring data. Prototipe software SCADA terlihat seperti pada gambar 8.

b. Tahap 2 : Integrasi peralatan baru meliputi sensor, level meter sesuai perencanaan disain untuk melengkapi pengamatan terhadap kualitas air. Pada tahap kedua ini perlu dilakukan pekerjaan-pekerjaan :

- Membuat protocol komunikasi sesuai dengan peralatan sensor yang baru.

- Upgrade pengembangan software SCADA versi kedua untuk montioring data. c. Tahap 3 : Pengembangan sistem controling hardware melalui software SCADA versi ketiga. Pada tahap ketiga ini pekerjaan lebih dititikberatkan pada masalah kontrol jarak jauh untuk peralatan yang sudah terpasang pada pekerjaan tahap 1 dan 2 menggunakan sistem jaringan dengan beberapa LC (Lean Control).

\subsection{Perencanaan Impelentasi dan Uji Coba}

Pekerjaan implementasi di lapangan dilakukan sesuai dengan tahapan perencanaan pembangunan, yakni :

a. Tahap 1 :

- Pemasangan kembali / reinstall peralatan sensor yang ada ke sistem control / data logger yang baru sehingga dapat dimonitor di ruang control.

- Integrasi peralatan kelistrikan pompa dan lain-lain agar dapat dimonitor status kerjanya di ruang control.

- Instalasi sistem software SCADA versi pertama yang mampu memonitor kualitas air dan status pompa di setiap proses pengolahan air.

b. Tahap 2 :

- Pemasangan peralatan sensor baru untuk lokasi pengamatan sesuai dengan rencana pengembangan ke sistem control / data logger sehingga dapat dimonitor di ruang control. 
- Instalasi sistem software SCADA versi kedua yang mampu memonitor kualitas air secara keseluruhan dan status pompa di setiap proses pengolahan air.

c. Tahap 3 :

- Pemasangan sistem control / data logger yang mampu mengontrol pengambilan data kualitas air dan mengendalian kerja peralatan pompa dari ruang kontrol melalui komputer.

- Instalasi sistem software SCADA versi ketiga yang mampu memonitor dan mengontrol kualitas air secara keseluruhan dan status pompa di setiap proses pengolahan air.

\section{KESIMPULAN}

1. Dalam literatur "Japan Water Works Association" disarankan memantau berbagai macam parameter kualitas air di setiap proses pengolahan air. Sistem SCADA yang dirancang tidak memantau semua parameter yang disarankan oleh literatur ini, namun hanya memantau beberapa parameter yang dianggap paling penting dan mewakili di setiap proses pengolahan air di WTP domestik.

2. Sistem SCADA untuk WTP domestik dirancang agar dapat menggunakan peralatan sensor yang ada di pasaran.
Perbedaan sistem komunikasi dari berbagai vendor peralatan sensor dapat diatasi dengan melakukan pekerjaan interfacing dengan panduan dari buku manual operasi yang diterbitkan oleh masing-masing vendor.

3. Sistem LC yang digunakan dirancang agar dapat dikonfigurasi dengan mudah yang disesuaikan dengan peralatan sensor yang digunakan.

4. Media komunikasi menggunakan kabel UTP adalah solusi termurah pada saat implementasi di lapangan. Namun demikian penggunaan media komunikasi dengan teknologi wireless dimungkinkan untuk menghubungkan peralatan komunikasi yang terletak jauh dari ruang kontrol, misalnya peralatan CCTV untuk mengirimkan data visualisasi lokasi intake sumber air baku.

\section{DAFTAR PUSTAKA}

1. PT. Jababeka - 2007, Survei Kondisi Existing WTP Perumahan di PT. Jababeka Tahun 2007,

2. Japan Water Works Association - 1978, Design Criteria for Waterworks Facilities Chap. 10. Measuring Instruments

3. SEI - 2007, I - Panel System, System Engineering Integrator.

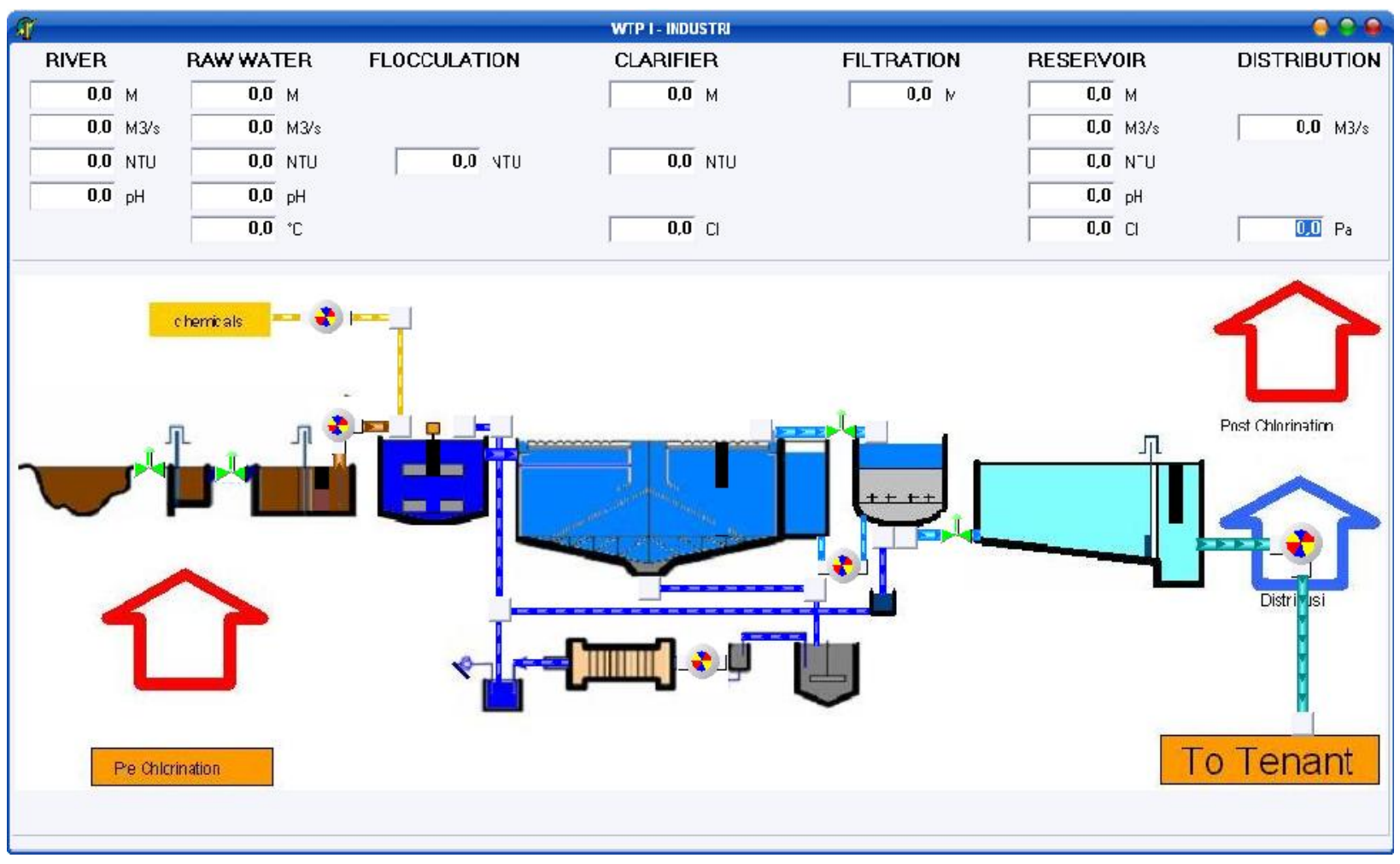

Gambar 8. Prototipe Software SCADA 


\section{LAMPIRAN}

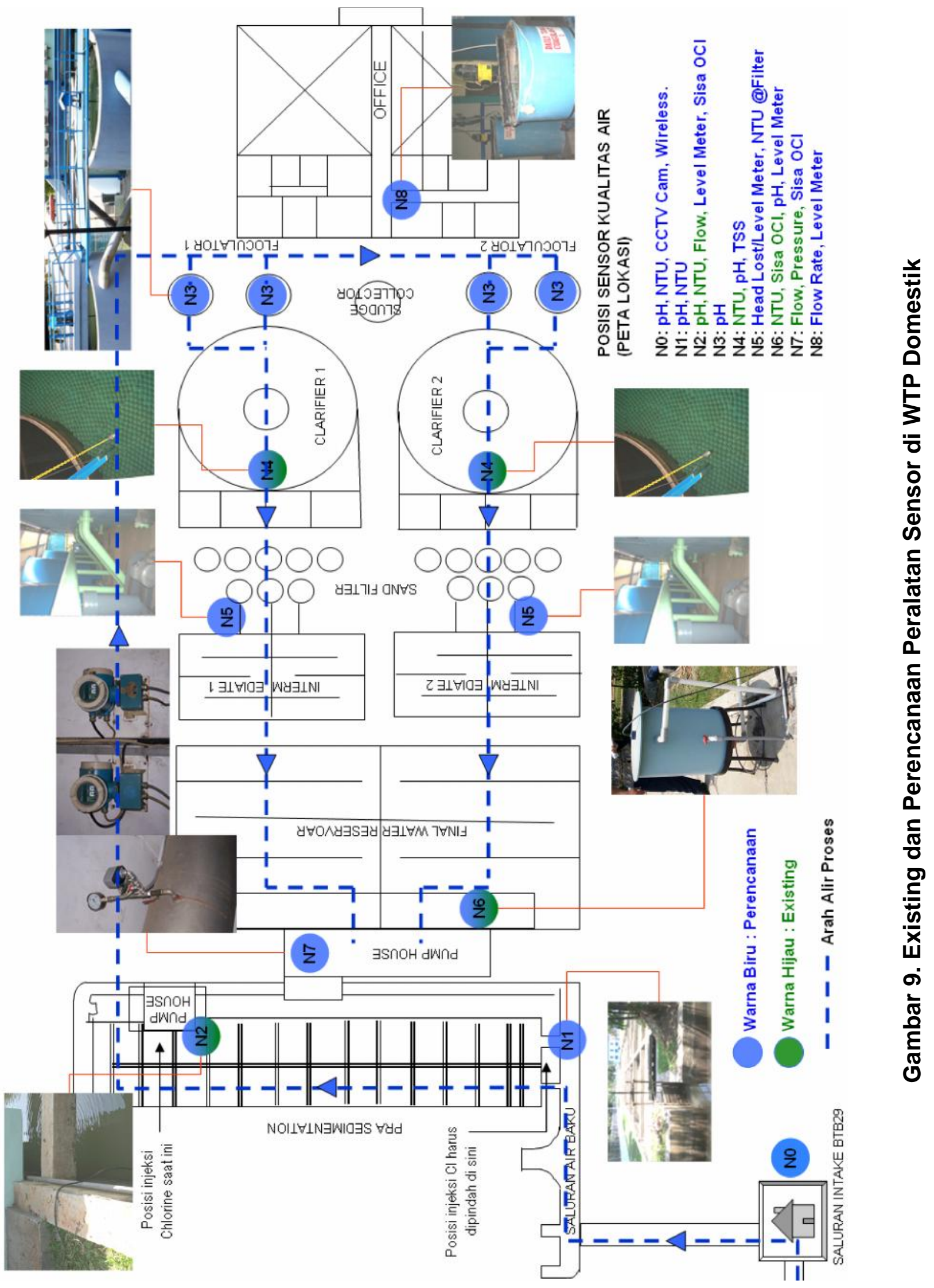




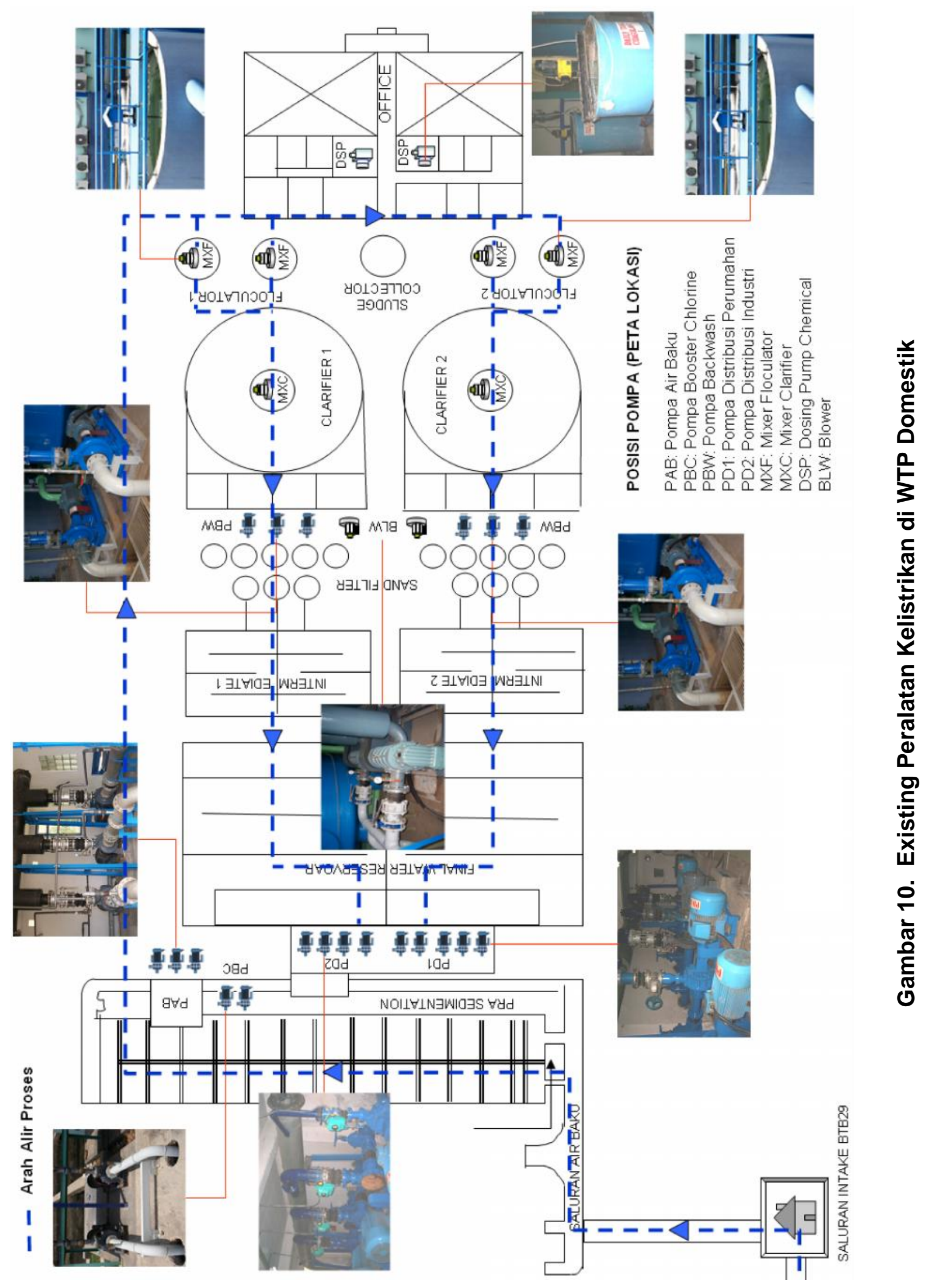




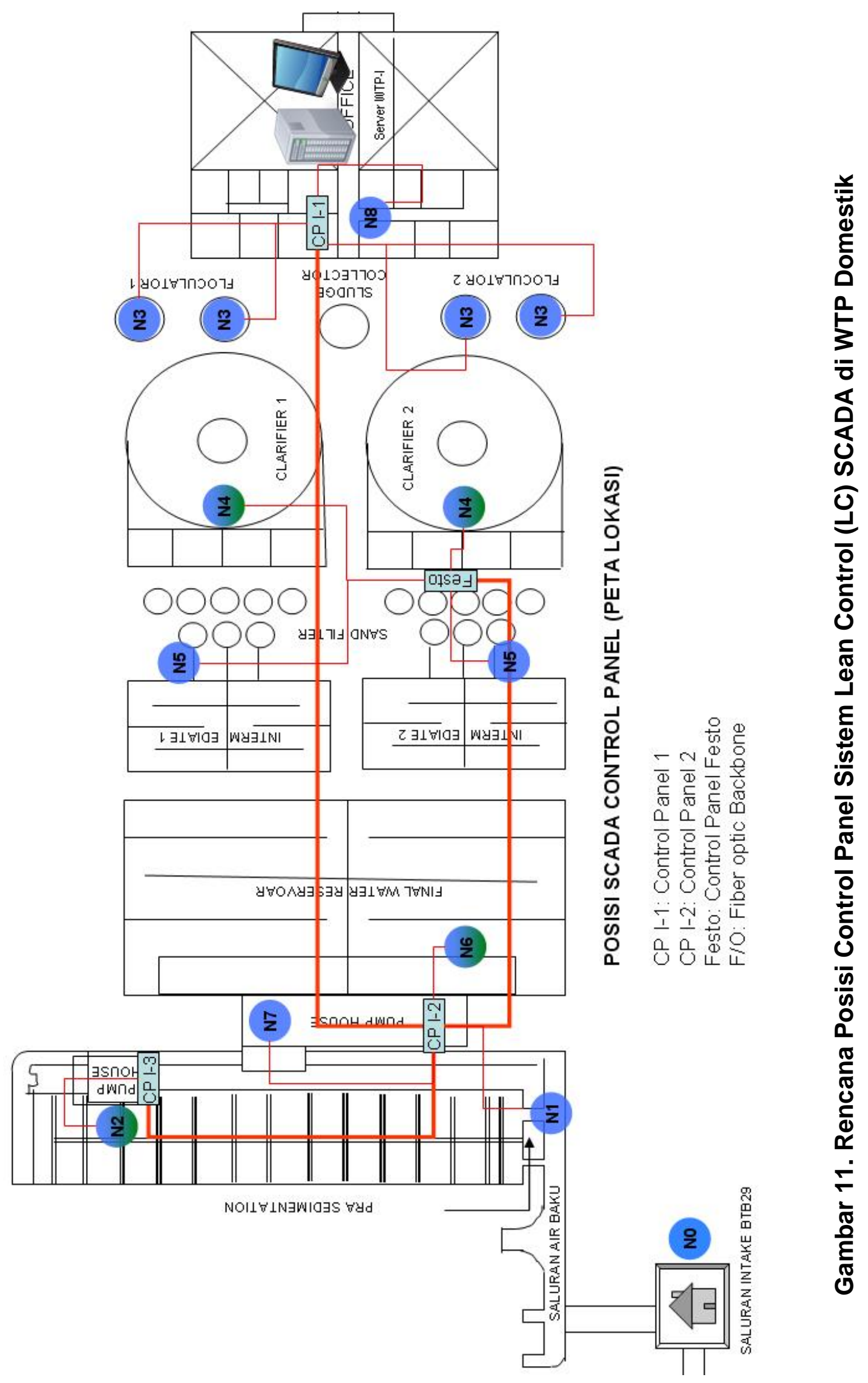

